\title{
LA FÁBRICA DE CERVEZAS "EL ÁGUILA" DE MADRID/ESPAÑA
}

\author{
("EL AGUILA" BEER FACTORY OF MADRID/SPAIN)) \\ Javier Gutiérrez Marcos, Arquitecto \\ Jefe del Servicio de Promoción del Patrimonio Histórico de la Comunidad de Madrid
}

Fecha de recepción: 23-VI-97

\section{RESUMEN}

La fábrica de cervezas "El Águila" de Madrid presenta un alto interés. Por un lado, destacan sus valores, caracteristicos del modelo constructivo español del primer cuarto de este siglo; por otro, representa la adaptación de la arquitectura a un proceso industrial cambiante a lo largo de su historia.

La arquitectura se hace claramente dependiente de su función, del uso albergado, con una notable respuesta.

\section{SUMMARY}

"El Águila" beer factory of Madrid presents a high interest. On one hand, it enphasizes their formal values, which are characteristic of the constructive spanish model of the first quarter of this century, on the other it represents the adaptation of a changing industrial process along its history.

The architecture makes itself clearly dependent of its function, of its use, with a remarkable response.
La antigua fábrica de cervezas " $E l$ Águila" constituye, junto con la que fue fábrica de lámparas "Osram", el primer grupo de edificios de carácter puramente industrial -es decir, que en su día albergaron un proceso fabril- a los que se incoa expediente para su declaración como Bien de Interés Cultural en el ámbito territorial de la Comunidad de Madrid, de acuerdo con lo establecido en la vigente Ley del Patrimonio Histórico Español ${ }^{(1)}$.

El segundo de los edificios citados, la fábrica "Osram", se construye como fábrica de lámparas eléctricas de la DGA de Berlín y se sitúa en el paseo de Santa María de la Cabeza $n^{\circ} 46$, con vuelta a las calles Palos de la Frontera y Fray Luis de León. Se edifica entre 1914 y 1916 , según proyecto del ingeniero Alberto del Palacio Elissague -autor, entre otros edificios, de la estación de Atocha o del Mediodía, e ingeniero de los palacios de Cristal y de Velázquez, de El Retiro, obras de Ricardo Velázquez Bosco- y de Francisco Borrás Soler.

Se trata de un edificio muy urbano, a pesar de su carácter claramente industrial y de su concepción, muy funcional. Su planta es rectangular, de doble crujía, para permitir su diafanidad y versatilidad, los núcleos de comunicación vertical y de servicios se sacan de la trama ortogonal y se alojan en los extremos de la nave. De acuerdo con la memoria del proyecto original, el sistema constructivo empleado es, el generalmente llamado, "a ła catalana", pero su estructura lleva en el centro unos machones de hormigón, donde se emplea el sistema patentado "hormigón 
armado sistema Borrás”, que amplía, de modo notable, las luces de forjado, permitiendo la ampliación de las crujías. El autor del citado sistema estructural es Francisco Borrás Soler, colaborador de Alberto del Palacio en el proyecto ${ }^{(2)}$.

La denominada fábrica de cervezas "El Águila" se sitúa en la ciudad de Madrid, en el ensanche sur, zona que Carlos María de Castro había previsto como un barrio rural, de casas exentas y áreas de cultivo; si bien, al asentarse sobre esta parte de la metrópoli, planificada para los accesos a Madrid por ferrocarril, con la construcción de las estaciones de Delicias (línea MCP -Madrid, Cáceres, Portugal) y los diferentes enlaces ferroviarios (estaciones de Peñuelas y de "La Pulga"), se va a modificar su desarrollo y las tipologías edificatorias que en él se implantan.

Su estructura y carácter urbano va a ser más parecido a lo que Castro había previsto en su Plan para los barrios de Chamberí, barrio industrial y Pacífico, de abastecimiento, depósito y abastos.

En este ensanche al sur, se van a situar las instalaciones industriales y de almacenamiento; las grandes estaciones, magníficos ejemplos de la arquitectura del hierro del último tercio del siglo XIX; las compañías de transformación y suministro de gas y electricidad, para dar servicio a la nueva ciudad y las instalaciones municipales de mataderos y mercados centrales de abastos. Sobre una preexistente trama barroco-borbónica se desarrolla, a finales del siglo XIX y hasta bien entrado en siglo XX, el barrio obrero, por excelencia, de Madrid, donde las industrias comparten su espacio con las viviendas en las que se asientan las clases trabajadoras relacionadas con la especialización funcional de este área de población.

Éste es el ámbito geográfico, histórico y social sobre el que se implanta el conjunto de referencia. El grupo de edificaciones se sitúa entre las calles del General Lacy, Ramírez de Prado, Vara del Rey y Bustamante. Se trata de un complejo fabril iniciado entre 1912 y 1914 y que es objeto de sucesivas intervenciones y ampliaciones, que se adaptan a las necesidades del proceso productivo de cada momento. Los edificios se agrupan, sin un orden arquitectónico preestablecido, sobre una parcela irregular del ensanche, de $119 \times 110$ metros, con un chaflán en su ángulo suroeste y situada al norte de la estación de Delicias y enfrentada a ella.

Las obras iniciales se llevan a cabo según proyecto del arquitecto Eugenio Jiménez Corera -autor, entre otros

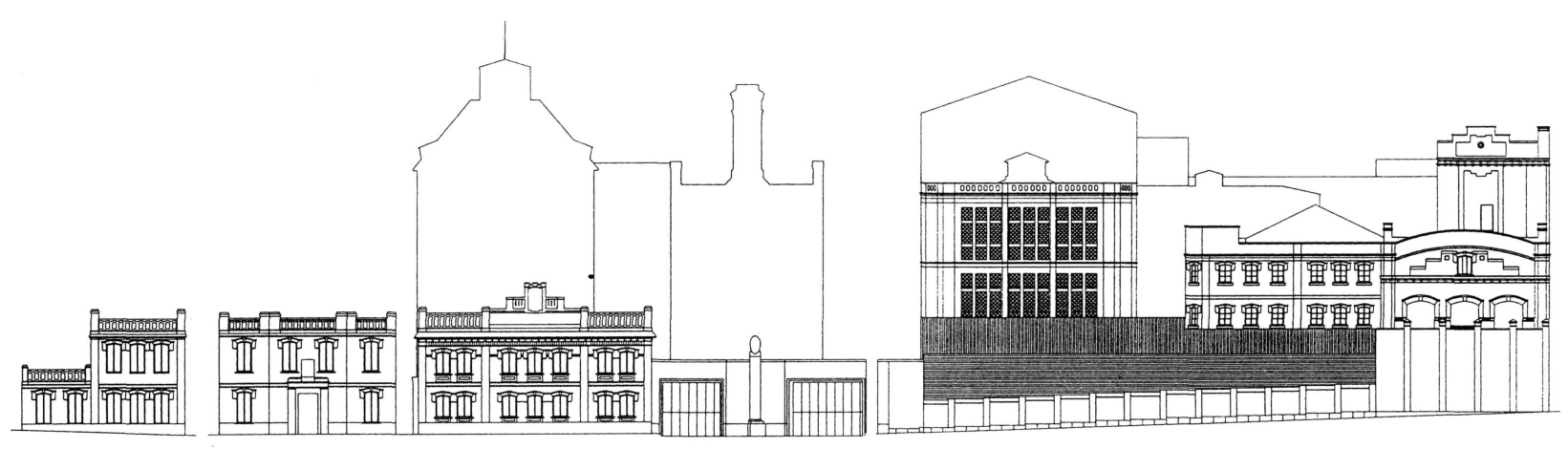

Alzado a calle Ramirez de Prado.

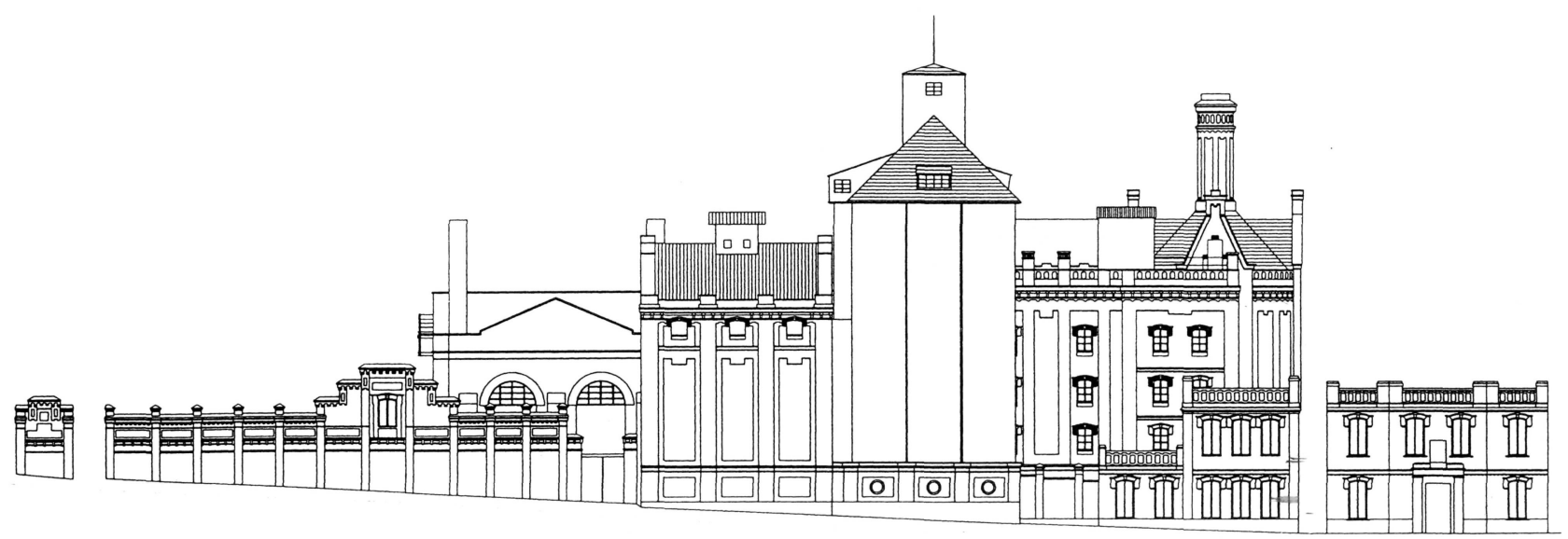

Alzado a calle General Lacy. 
edificios, de las iglesias de San Fermín de los Navarros y de la de la Concepción y del asilo de la Purisima Concepción, en Pacífico-, en el período 1912-1914 y se continúan, según el proyecto de Luis Sáinz de los Terreros -autor de la actual embajada de Bélgica en la calle Padilla y del edificio del Círculo de la Unión Mercantil e Industrial en la Gran Vía madrileña- en su fase de 1925-1927.

Para poder analizar cada una de las construcciones que constituyen este interesante conjunto de producción, seguimos el orden establecido en el expediente incoado para su declaración como Bien de Interés Cultural:

\section{Volumen I: módulo de cocheras y caballerizas}

Formado por dos cuerpos edificatorios contiguos e independientes, delimitando la alineación de la calle Bustamante. Se construyen entre 1914 y 1925 . Pese a las transformaciones sufridas a lo largo del tiempo, conservan su estructura de edificios industriales de carácter auxiliar. Se trata de las edificaciones más bajas del grupo, con fábricas de ladrillo y cerchas metálicas. Las caballerizas, que conforman la esquina de la calle Bustamante con la de General Lacy, se levantan en 1914, conservando su volumen y características iniciales.

En 1936, los garajes originales se convierten en talleres. La parte que ocupaba la esquina de la calle Bustamante con la de Vara del Rey, se sustituye, en los años sesenta, por una edificación de oficinas y administración, fuera de contexto en el conjunto.

\section{Volumen II: módulo de proceso o pabellón de producción}

Constituido por las secciones de heladora, máquinas, cocción y molino y cocción y calderas. Este edificio, de planta rectangular y alargada, define, junto con el de la maltería, la calle interior del conjunto, calle en la que se sitúa la línea férrea que da servicio a la fábrica y la conecta con la estructura ferroviaria de la próxima estación de Delicias, al otro lado de la calle Ramírez de Prado.

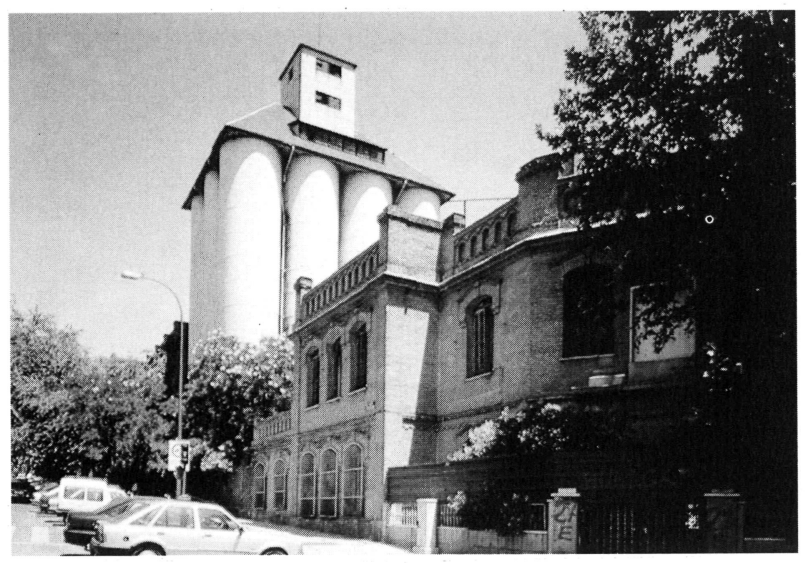

lista del conjunto desde la calle (ieneral Lacy.

(c) Consejo Superior de Investigaciones Científicas Licencia Creative Commons 3.0 España (by-nc)

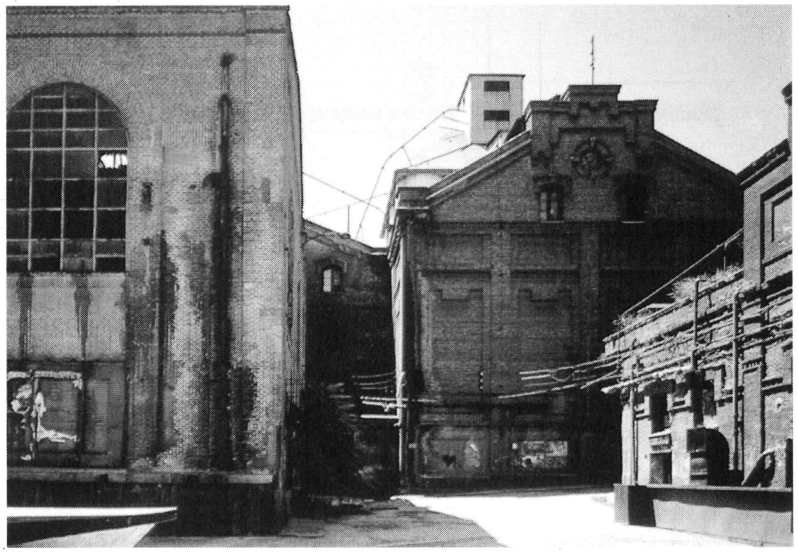

Heladora y cocheras

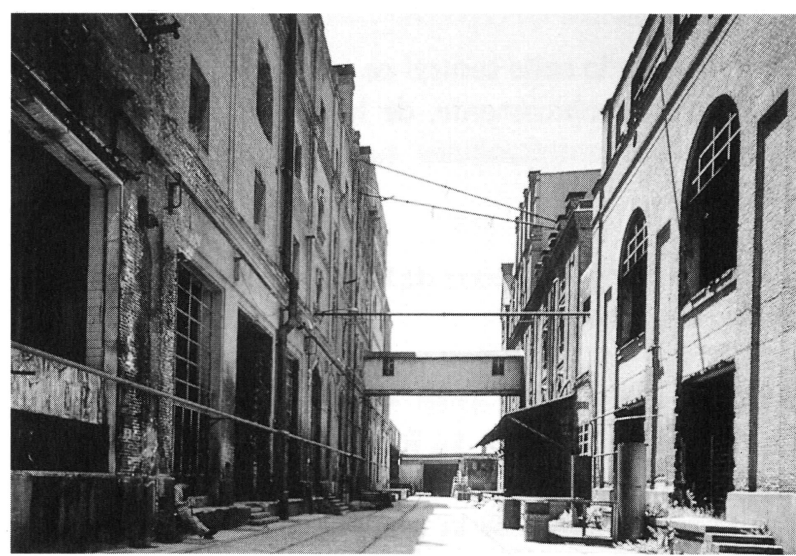

Calle interior:

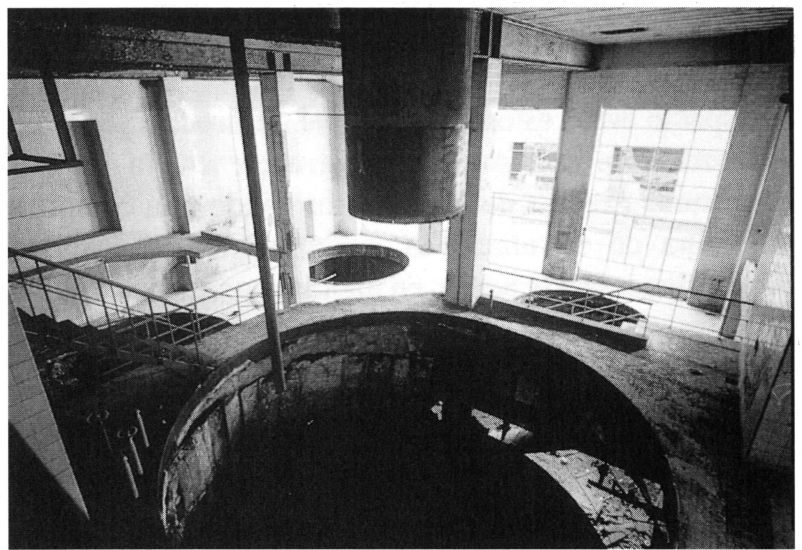

Interior edificio de producción.

Se levanta hacia 1914, mediante una sólida y potente estructura de muros de ladrillo y viguería y soportes metálicos en el interior.

El proceso de cocción exige importantes instalaciones interiores de calderería, depósitos y conducciones de todo tipo, instalaciones, todas ellas, que definen su estructura arquitectónica. Su aspecto final responde tanto al proceso 


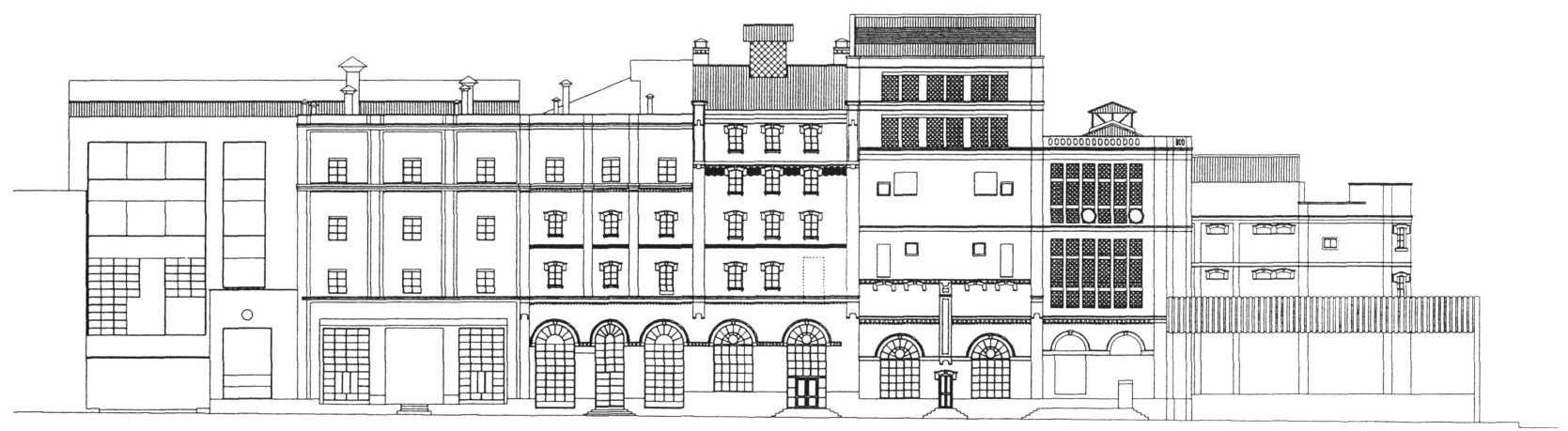

Módulo de proceso.

industrial como a las instalaciones y a las diferentes ampliaciones y adecuaciones que ha sufrido a lo largo de su historia.

Su fachada a la calle central es uno de los elementos más sugerentes, estéticamente, de la fábrica; los huecos, las celosías, las ampliaciones sucesivas, las instalaciones adosadas...

\section{Volumen III: pabellones de fermentación y almacenes.} Bodegas y depósitos

Bodegas y depósitos están situadas en la esquina que forman las calles Vara del Rey y Ramírez de Prado.

El almacenamiento de la producción exigía bodegas de gran tamaño, con un importante aislamiento. El núcleo inicial se realiza en 1914 y se va ampliando en sucesivas intervenciones: 1925-1927, hasta formar un grupo de edificios conexos, cuya principal característica estética quedaría definida por sus muros ciegos.

El espacio entrè estos cuerpos y el de producción acabó abarrotándose con nuevas construcciones, la mayoría estructuras exentas de fachada, formando una complicada trama de circulaciones, contenedores, depósitos e instalaciones que se adosa, en algunas zonas, al módulo de proceso.

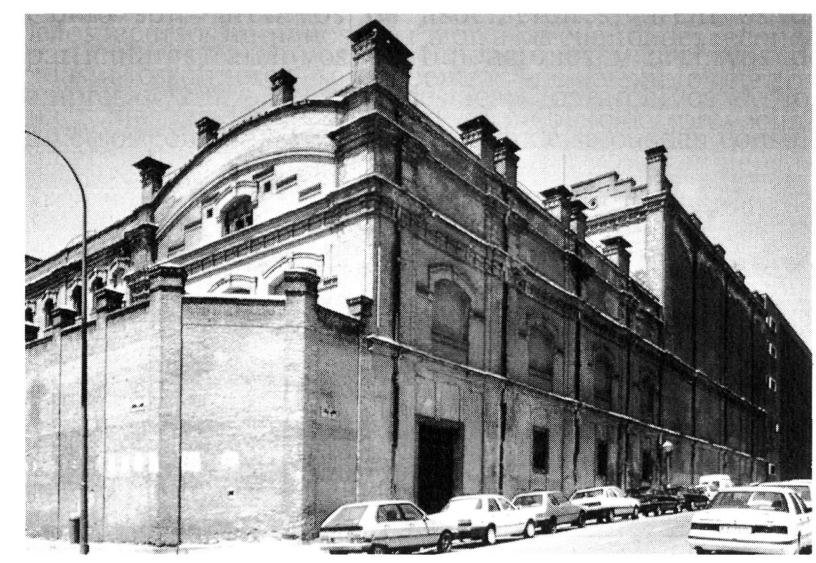

Almacenes a calle Vara del Rey.

(c) Consejo Superior de Investigaciones Científicas Licencia Creative Commons 3.0 España (by-nc)
Volumen IV: silos de cebada

Situados en el centro de la fachada de la calle General Lacy

Los primeros silos se construyen en la ampliación de 1926 y se adosan a la maltería. Se trata de un grupo de doce vasos cuadrados, de 17 metros de altura, ejecutados en hormigón, con un cerramiento perimetral de ladrillo, de factura neomudéjar y de planta rectangular. Se cubren a dos aguas, mediante cerchas de madera.

En 1933, en el lugar que ocupó el antiguo molino, junto a los otros silos y los pabellones de oficinas, se elevan los nuevos silos metálicos, de 18 metros de altura interior, constituidos por doce cilindros de chapa, que conforman un único cuerpo sobre un basamento de fábrica de ladri1lo. Se cubren mediante una estructura a cuatro aguas y pizarra. Se formaliza como una de las imágenes más nítidas y contundentes del conjunto y como posible señal de identidad.

\section{Volumen V: heladora}

Este elemento se sitúa en la posición central de la parcela, junto a la maltería y, como ya se ha dicho, conforma, junto con el módulo de proceso, la calle central del conjunto.

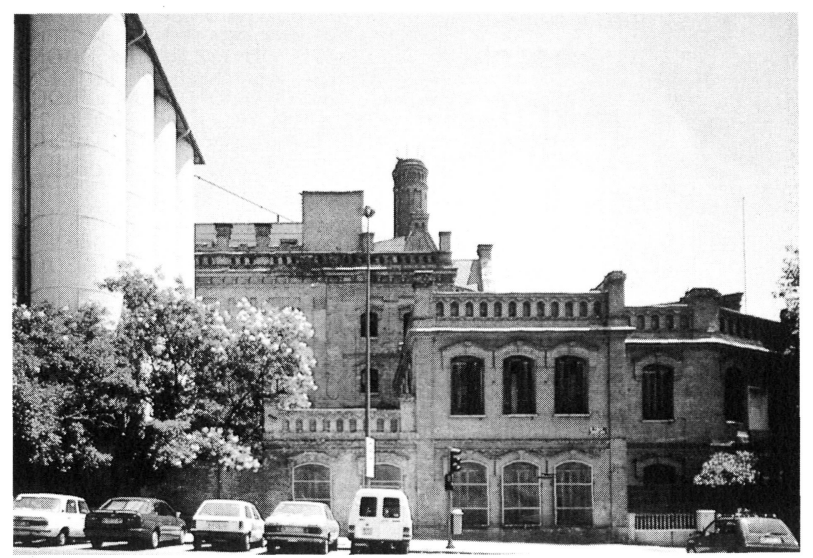

Silos muevos y edificio administrativo. 


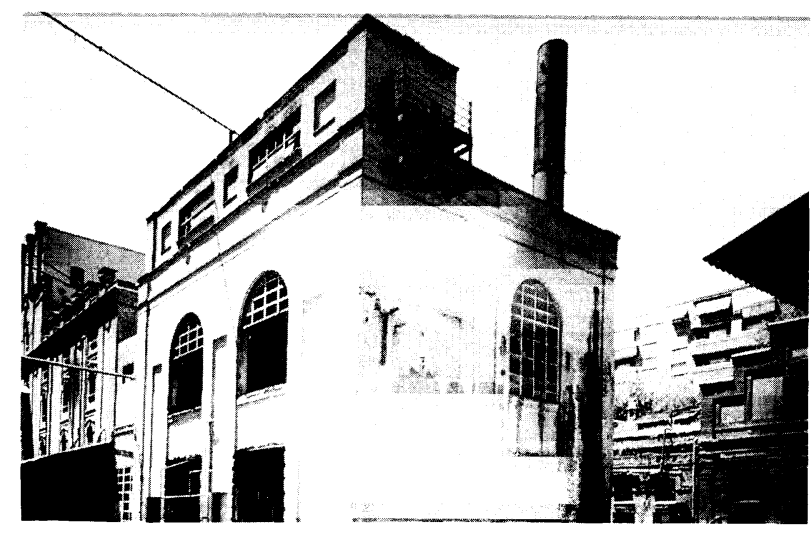

Heladora.

Se edifica hacia 1925 como heladora; si bien, en los últimos años de vida de la fábrica, se utilizó para la ubicación de las calderas.

Se trata de un contenedor prismático, de unos 12 metros de altura libre, sin forjados o estructuras interiores. El cerramiento exterior es de fábrica de ladrillo y presenta grandes huecos, rematados por arcos de medio punto.

\section{Volumen VI: maltería}

Se ubica al lado de la heladora. Se trata del edificio más significativo y de arquitectura más contundente. Es uno de

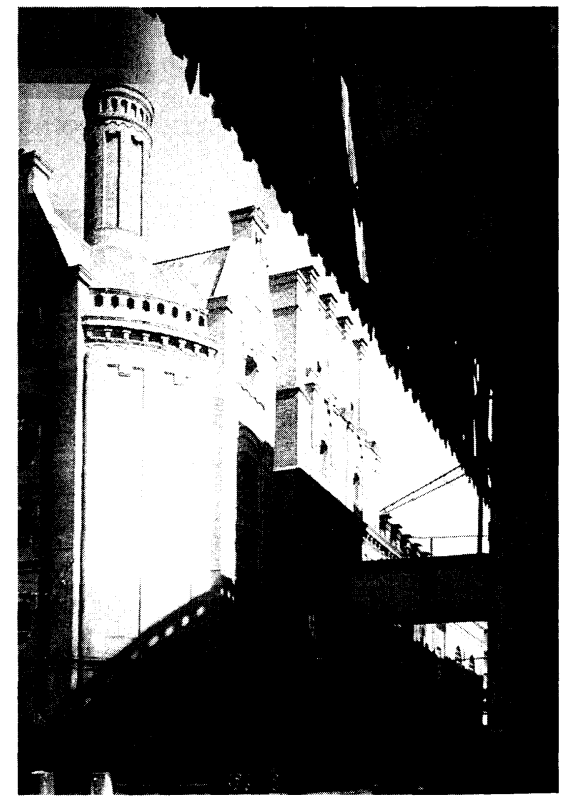

Malteria.

los edificios iniciales del conjunto, de los más antiguos y en el que se llevaron a cabo la mayor parte de los primeros procesos de fabricación de la cerveza.

Se configura mediante un cuerpo cilindrico, de 12 metros de diámetro, lo que fuera el horno de secado del grano, rematándose mediante una gran chimenea de ladrillo; y de
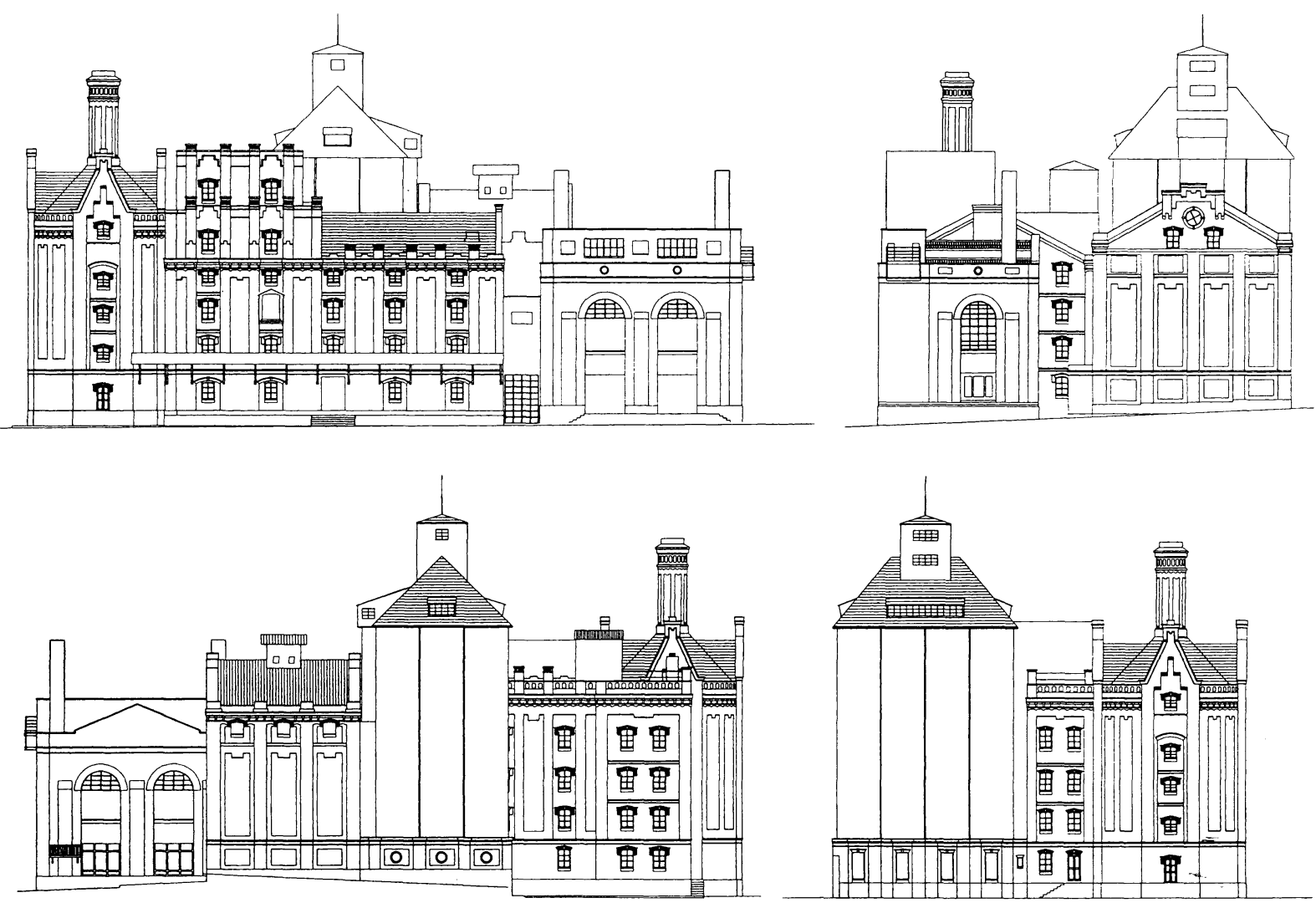

Malteria, heladoray silos. 


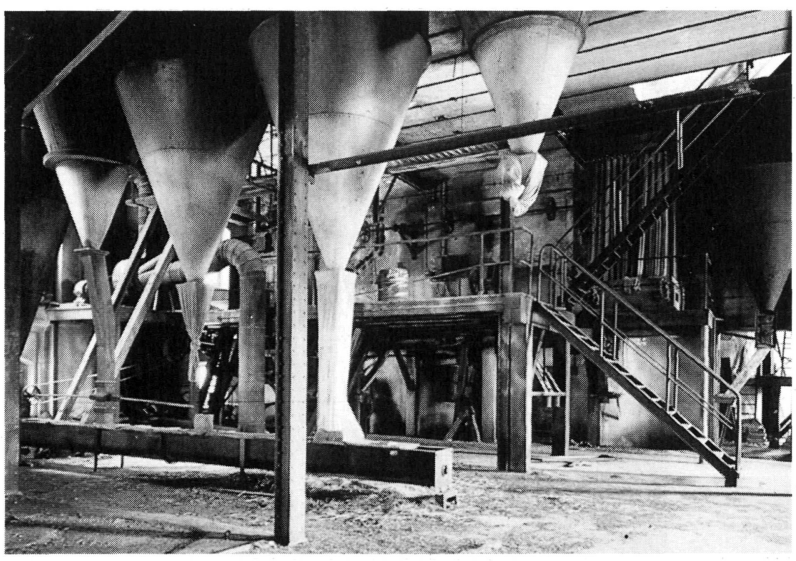

Maquinaria edificio de la malteria.

otro cuerpo, alargado, de planta rectangular, de $29 \times 19$ metros, que contiene los restos de la maquinaria original, importante muestra de arqueología industrial. Ambos cuerpos se unen por otro, que les sirve de comunicación.

Aunque sus fábricas de ladrillo son de factura neomudéjar, su volumen y su tipología arquitectónica podría relacionarse con modelos fabriles del racionalismo centroeuropeo. Su rotundo volumen y la calidad del diseño de sus huecos y de los paños ciegos de sus fábricas, le hacen destacar como una de las mejores piezas de la arquitectura industrial madrileña del primer cuarto del siglo XX. Además, contiene notables piezas de la maquinaria inicial que merecen ser objeto de conservación en sí mismas, con independencia de los valores arquitectónicos del contenedor.

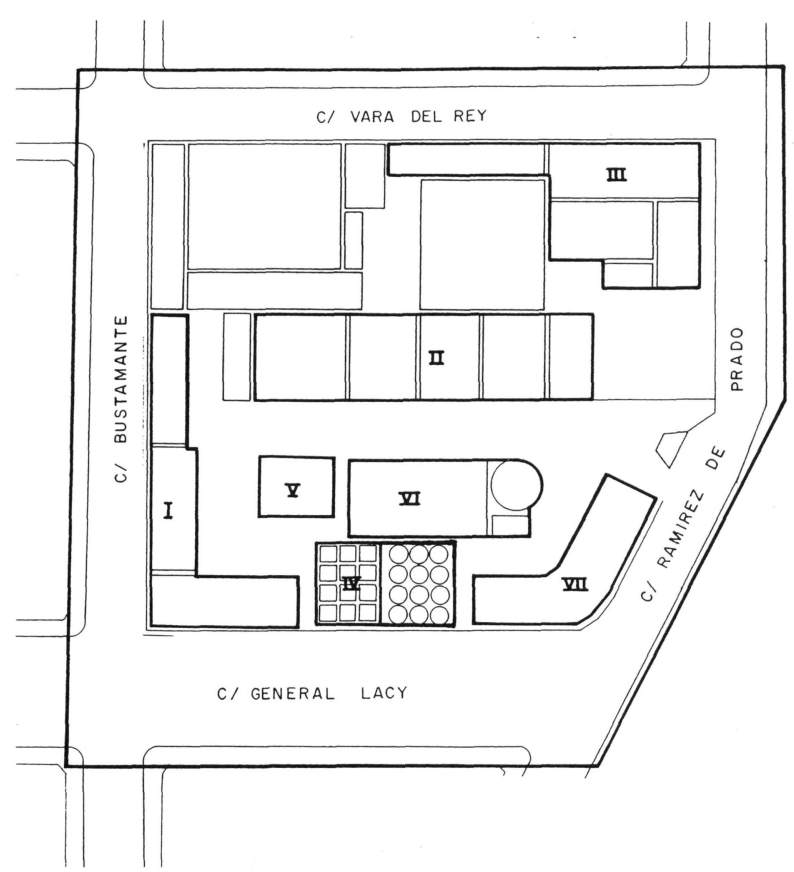

Referencia de volúmenes. I: módulo de cocheras y caballerizas. II: módulo de proceso o pabellón de producción. III: pabellones de fermentación y almacenes. IV: silos de cebada. $V$ : heladora. VT: maltería. VTI: oficinas y administración.

(c) Consejo Superior de Investigaciones Científicas Licencia Creative Commons 3.0 España (by-nc)

\section{Volumen VII: oficinas y administración}

Esta edificación ocupa el chaflán formado por las calles General Lacy y Ramírez de Prado. Su construcción se lleva a cabo en diferentes períodos. El primer edificio se levanta hacia los años 1910-1914. Se trata de un pabellón rectangular, de 15 x 13 metros, de dos plantas y sótano, con estructura original de muros perimetrales de ladrillo y tres crujías interiores, mediante muros intermedios. Se cubre a dos aguas, por medio de estructura de madera.

La ampliación hacia la calle General Lacy se ejecuta en 1940 y otra, posterior, en 1954, siempre conservando el carácter inicial que sigue las directrices de la denominada arquitectura neomudéjar.

Las fábricas exteriores del conjunto de estos edificios son de ladrillo visto, con aparejos y decoración neomudéjar, con algunas zonas de cuidada ejecución y destacados detalles decorativos y azulejería.

Todo el espacio libre de la pasarela está ocupado por construcciones subterráneas, canalizaciones, tolvas de vertido de material, instalaciones y conducciones de todo tipo, que unen unos edificios con otros y que superponen el proceso de fabricación al espacio edificado.

Al exterior, el conjunto presenta un cerramiento de fábrica de ladrillo, sobre el que se destacan las piezas más significativas, en especial, las de las calles General Lacy y Ramírez de Prado.

\section{EL FUTURO}

Como quedó expuesto, la declaración como Bien de Interés Cultural pretendía la protección no sólo de algunas

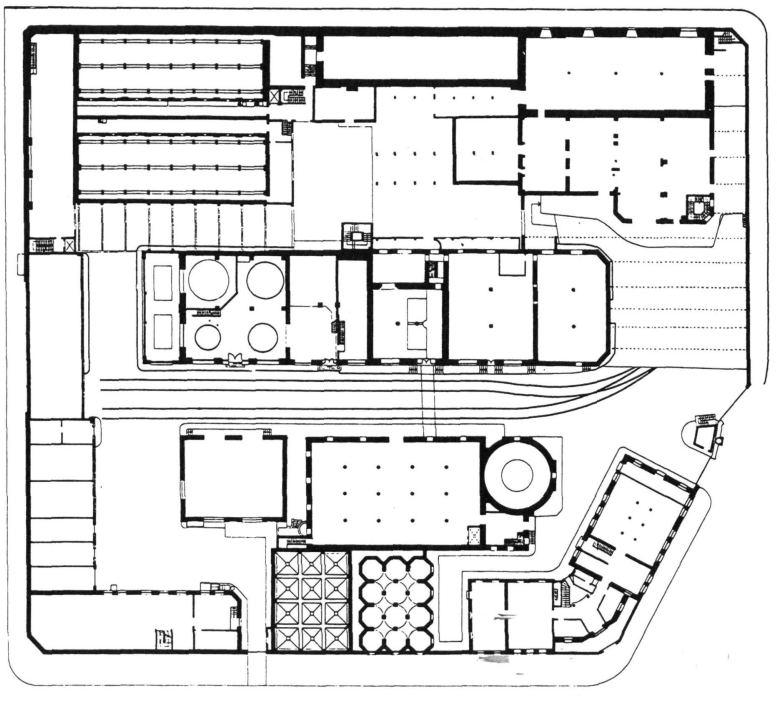

Planta general del conjunto. 
edificaciones del conjunto, las más significativas; también la protección de determinada maquinaria y elementos característicos del proceso de producción.

En este orden de cosas y en aras a una mejor protección del conjunto edificado, la Comunidad de Madrid, a través de la Consejería de Educación y Cultura, accedió a la propiedad, con el fin de poner en valor sus elementos más representativos. Para ello, se propuso la ubicación, en las construcciones de más valor del conjunto, del Centro de las Artes y la Cultura de la Comunidad de Madrid.

Este Centro constituía un ambicioso programa de espacios para las artes plásticas y escénicas; infraestructuras culturales, como la biblioteca especializada de la Comunidad de Madrid, así como un centro académico, la escuela Superior de Diseño, además de servicios generales, salas de producción y alquiler, comercio del arte...

A tal efecto, se convocó un concurso de ideas arquitectónicas a nivel nacional que se desarrolló en dos fases. En la primera, el jurado del concurso seleccionó un total de veinte equipos entre los ciento ochenta y seis inicialmente inscritos, basándose en el currículo (relacionado con el asunto del concurso) que presentó cada uno de ellos. En la segunda fase, estos veinte equipos seleccionados, presentaron sus propuestas.

Además de un programa detallado -que había sido objeto de otro concurso-, con el objeto de definir las necesidades de uso, para cada una de las áreas de actividad anteriormente expuestas, las bases del concurso establecían unos criterios de conservación para las edificaciones de la fábrica en tres niveles diferentes y una, de las recomendaciones sobre localización de las actividades.

El juradoestuvo presidido por Jaime Lissavetzky, consejero de Educación y Cultura, y formado por Ramón Caravaca, viceconsejero de Educación y Cultura; Miguel Ángel Castillo, director general de Patrimonio Cultural; Carlos Jiménez, gerente del Centro de Estudios y Actividades Culturales; Antonio Fernández Alba, arquitecto, representante de los concursantes; Manuel Rivero, arquitecto, designado por el Ayuntamiento de Madrid; Ricardo Núñez, arquitecto, designado por el Colegio de Arquitectos de Madrid como vocal, y Javier Gutiérrez, arquitecto, jefe del Servicio de Conservación y Restauración del Patrimonio Histórico Inmueble, que actuó como secretario.

Las citadas bases establecían los siguientes criterios para valorar las propuestas presentadas: calidad arquitectónica, adecuación de las superficies al programa planteado y su relación con la localización de actividades, intervención realizada sobre el conjunto de los edificios en sus diferentes niveles de conservación, viabilidad de ejecución de las obras y su capacidad de adaptación a una realización por fases y, por último, la problemática derivada del cumplimiento de la normativa urbanística.

Después de analizar las diferentes propuestas que se presentaron bajo lema y tras manifestar la gran calidad de los trabajos, que en su mayoría se ajustaban al espíritu de las bases, con una variedad de notable interés arquitectónico, el jurado, por unanimidad, propuso la concesión del primer premio al trabajo de Emilio Tuñón y Luis Moreno, valorando "su adecuación al programa, con la resolución de las diferentes actividades culturales solicitadas con gran claridad arquitectónica, su viabilidad para el desarrollo y ejecución del proyecto con una delicada recuperación del conjunto histórico en coherencia con el entorno urbano y la singular calidad que encierra su diseño y propuesta" (3).

En la actualidad, por motivos de diversa índole, se ha desistido en la creación del Centro de las Artes y la Cultura $\mathrm{y}$, en su lugar, por los arquitectos ganadores del concurso

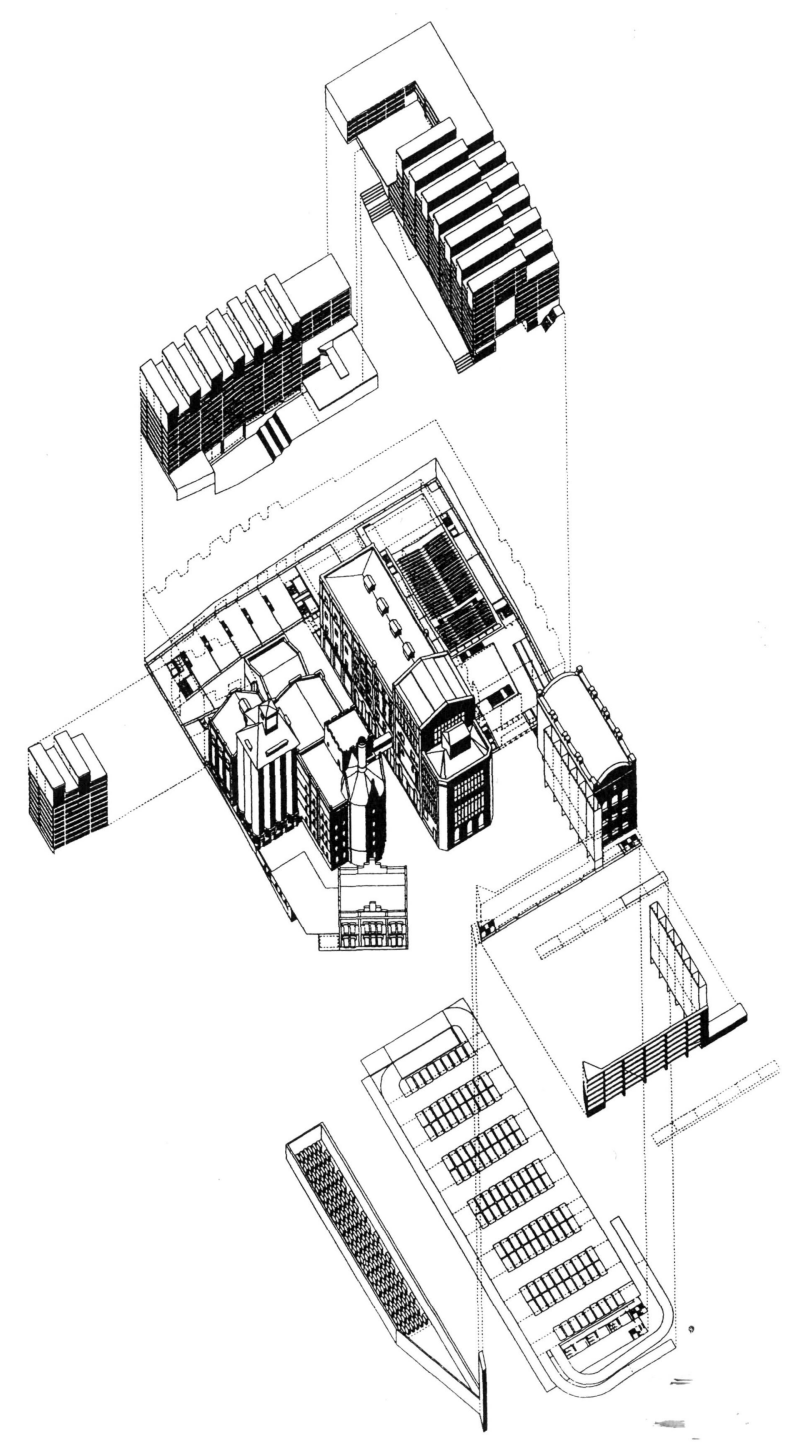

Proyecto ganador del concurso. Tuñón y Moreno. 
se trabaja en el proyecto de ejecución para la adaptación de los edificios a Biblioteca y Archivo Regionales de ia Comunidad de Madrid.

Sería deseable que los nuevos proyectos no sólo recuperaran y mantuviesen los edifícios históricos, sino también sus sistemas constructivos y los restos de las instalaciones y de los procesos industriales, maquinarias, depósitos... que deberán quedar integrados en los nuevos usos como objetos de indudable valor arqueológico industrial.

\section{Notas}

(1) Ley 16/1985 del Patrimonio Histórico Español.

Resolución de 3 de diciembre de 1990 dela Dirección General de Patrimonio Cultural de la Consejería de Cultura, por la que se acuerda tener por incoado expediente de declaración de Bien de Interés Cultural, con la categoría de Monumento, los edificios de la fábrica de cervezas "El Águila", sita en la calle General Lacy $\mathbf{n}^{\circ} 25$, de Madrid.
La fábrica "Osram" tiene incoado expediente para su declaración como Bien de Interés Cultural, en la categoría de Monumento, por Resolución de 25 de febrero de 1991.

(2) Véase Guía de Arquitectura y Urbanismo de Madrid. Tomo II. Varios autores (Colegio Oficial de Arquitectos de Madrid), $1^{\text {a }}$ edición. Madrid, diciembre 1983.

El autor del presente artículo fue miembro del equipo de investigación y redacción de la guía de referencia. En ella se pueden analizar otros edificios industriales madrileños coetáneos a los citados.

(3) Véase El Águila. Concurso para Centro de las Artes y la Cultura de la Comunidad de Madrid. Separata de la revista "Arquitectos" $n^{\circ} 138$, editada por la Comunidad de Madrid y por el Consejo Superior de los Colegios de Arquitectos de España. Madrid, 1996.

\section{Fotografías y planos}

Archivo de la Dirección General de Patrimonio Cultural de la Comunidad de Madrid.

\title{
Publicación del Instituto Eduardo Torroja - CSIC
}

\author{
Número monográfico de INFORMES
}

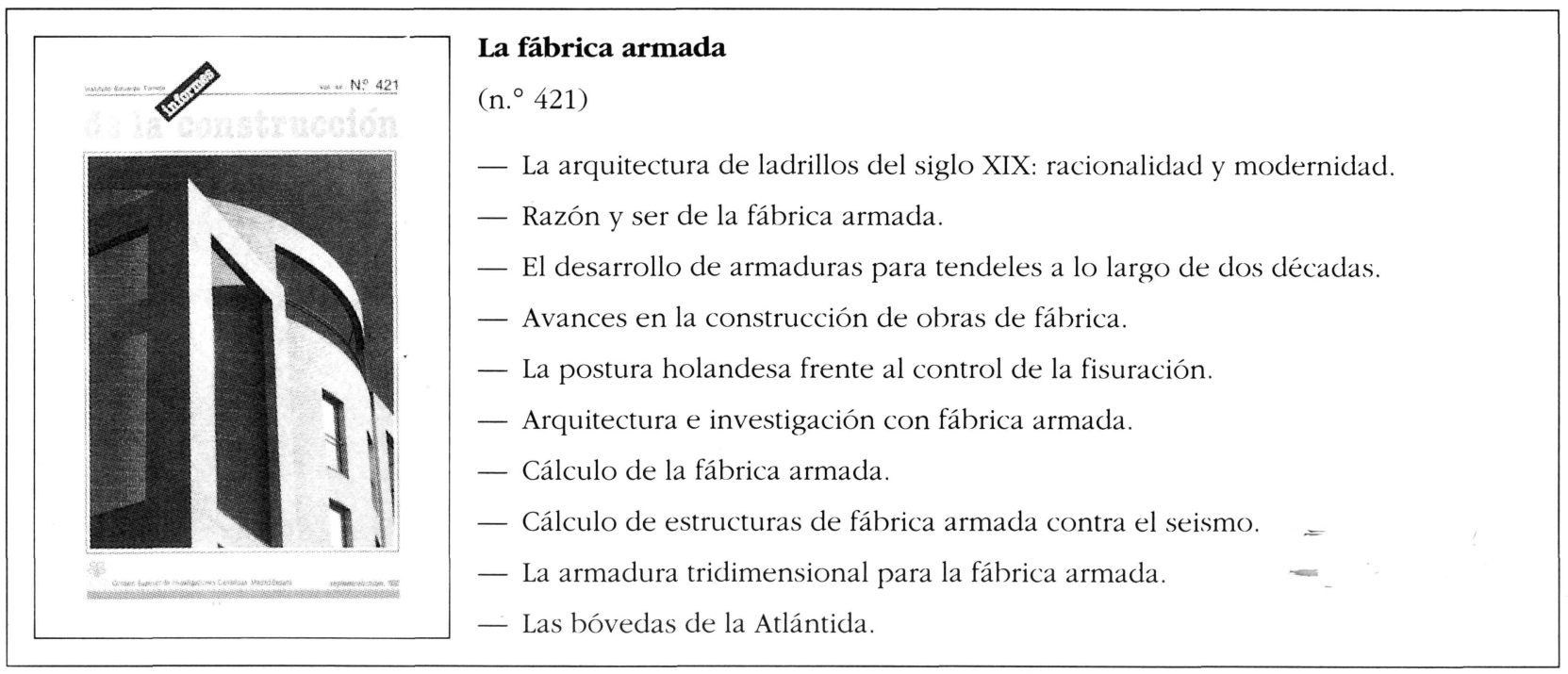

